\begin{tabular}{|c|c|c|c|c|c|c|}
\hline $\begin{array}{l}\text { Incomes } \\
\text { Medications }\end{array}$ & $\mathbf{N}$ & Mean & Std. Deviation & Median & Minimum & Maximum \\
\hline \multicolumn{7}{|l|}{ Steroids } \\
\hline No & 91 & 43955 & 10357 & 40565 & 17946 & 67091 \\
\hline Yes & 12 & 39702 & 8927 & 39643 & 32285 & 63629 \\
\hline \multicolumn{7}{|l|}{ Hydroxychloroquine } \\
\hline No & 11 & 40530 & 7320 & 40159 & 31013 & 52924 \\
\hline Yes & 92 & 43810 & 10525 & 40159 & 17946 & 67091 \\
\hline \multicolumn{7}{|l|}{ Azathioprine } \\
\hline No & 85 & 43303 & 10028 & 40159 & 17946 & 67091 \\
\hline Yes & 18 & 44199 & 11541 & 41050 & 31977 & 66374 \\
\hline \multicolumn{7}{|l|}{ Gyclophosphamide } \\
\hline No & 102 & 43454 & 10304 & 40159 & 17946 & 67091 \\
\hline Yes & 1 & 44010 & & 44010 & 44010 & 44010 \\
\hline \multicolumn{7}{|l|}{ Methotrexate } \\
\hline No & 95 & 43282 & 10351 & 40159 & 17946 & 67091 \\
\hline Yes & 8 & 45567 & 9358 & 41625 & 38887 & 66374 \\
\hline \multicolumn{7}{|l|}{ Myocphenolate } \\
\hline No & 86 & 43809 & 10774 & 40362 & 17946 & 67091 \\
\hline Yes & 17 & 41689 & 7035 & 39808 & 32566 & 51055 \\
\hline \multicolumn{7}{|l|}{ Belimumab } \\
\hline No & 100 & 43369 & 10380 & 40159 & 17946 & 67091 \\
\hline Yes & 3 & 46468 & 3779 & 44574 & 44010 & 50819 \\
\hline \multicolumn{7}{|l|}{ Tacrolimus } \\
\hline No & 100 & 43709 & 10284 & 40362 & 17946 & 67091 \\
\hline Yes & 3 & 35124 & 4361 & 32646 & 32566 & 40159 \\
\hline \multicolumn{7}{|l|}{ Any of the above* } \\
\hline No & 4 & 40431 & 9947 & 38893 & 31013 & 52924 \\
\hline Yes & 99 & 43582 & 10296 & 40159 & 17946 & 67091 \\
\hline
\end{tabular}

*p-value $=0.592$ (Mann-Whitney U Test)

\section{ANA-NEGATIVE SLE: RE-EVALUATION IN AN INTERNATIONAL INCEPTION COHORT}

${ }^{1} \mathrm{M} \mathrm{Choi}^{*},{ }^{1} \mathrm{~A}$ Clarke, ${ }^{2} \mathrm{St}$ Pierre Y., ${ }^{3}$ Hanly, ${ }^{4} \mathrm{M}$ Urowitz, ${ }^{4} \mathrm{D}$ Gladman, ${ }^{2} \mathrm{~S}$ Pike, M. Fritzler ${ }^{1}$ ${ }^{5}$ SI SLICCInvestigators Group. ' University of Calgary, Medicine, Calgary, Canada; ${ }^{2}$ McGill University, Medicine, Medicine, Canada; ${ }^{3}$ Queen Elizabeth II Health Sciences Centre and Dalhousie University, Medicine, Halifax, Canada; ${ }^{4}$ University of Toronto, Medicine, Toronto, Canada; ${ }^{5}$ Allegheny Health Network, Medicine, Pittsburgh, USA

\subsection{6/lupus-2017-000215.400}

Background and aims The prevalence of ANA-negative SLE is reportedly 5\%-20\%. Cytoplasmic or mitotic cell indirect immunofluorescence (IIF) patterns are usually reported as ANA-negative. This study examined the prevalence of ANAnegativity (no intracellular IIF pattern) and pure cytoplasmic and/or mitotic IIF patterns (CMP) in the Systemic Lupus International Collaborating Clinics (SLICC) inception cohort and examined demographic, clinical and autoantibody associations.

Methods Three groups were examined 1) ANA-positive (presence of nuclear IIF pattern), 2) ANA-negative (no IIF pattern), and 3) pure CMP. ANA were detected by IIF on HEp-2000 substrate, SLE-related autoantibodies by laser bead immunoassay, and anti-dsDNA and anti-dense fine speckles 70 (DFS70) by chemiluminescence immunoassay.

Results 1137 patients were included; 89.9\% were female. 92.3\% were ANA-positive, 6.2\% were ANA-negative, and $1.5 \%$ had a CMP. In the multivariate analysis (Tables 1 and 2), patients from Canada (Odds Ratio (OR) 2.07 [95\% CI: $1.28,3.36]$ ) or with anti-DFS70 (OR 4.45 [95\% CI: 1.37, 14.39]) were more likely to be ANA-negative or have CMP. Patients of Asian descent (OR 0.34 [95\% CI: 0.13, 0.86]) or with anti-dsDNA (OR 0.53 [95\% CI: 0.30, 0.94]), anti-SSA/
Ro60 (OR 0.51 [95\% CI: $0.30,0.87]$ ), or anti-UI-RNP (OR 0.35 [95\% CI: $0.17,0.70])$ were less likely to be ANA-negative or CMP.

Conclusions In newly diagnosed SLE, the prevalence of ANAnegativity was at the lower end $(6.2 \%)$ of the range previously published and an additional $1.5 \%$ had a CMP pattern. The prevalence of true ANA-negativity will likely decrease as future guidelines are expected to recommend that non-nuclear patterns, such as CMP, are also reported.

\section{HIGHEST FREQUENCY OF CLINIC VISITS AND HOSPITALIZATIONS IN SLE AMONG RHEUMATIC DISEASES: 8 YEAR CENSUS OF A TERTIARY RHEUMATOLOGY CENTRE}

ME Galdones-Velasco*, MFJ Edar, S Navarra. University of Santo Tomas, Internal Medicine, Manila, Philippines

\subsection{6/lupus-2017-000215.401}

Background and aims We describe the frequency of clinic visits and hospitalizations among rheumatic diseases seen at a tertiary Rheumatology centre in Manila, Philippines

Methods The University of Santo Tomas (UST) Hospital is a tertiary care centre, with specialised subspecialty training in Rheumatology. This study is derived from the patient census of UST Hospital Rheumatology Clinics from 2008 to 2015.

Results Mean age of the total 15730 rheumatic disease patients (10 808, 69\% females; 13 607, 86.5\% adults; 2123, $13.5 \%$ paediatrics) was $47.51 \pm 21.55$ (range $<1-103$ ). Most common rheumatic conditions were osteoarthritis (OA) (2828, $17.98 \%)$, gout/pseudogout $(2378,15.12 \%)$ and systemic lupus 